\title{
Research Article \\ Relationship Between Finnish Diabetic Risk Score (FINDRISC) with Health-Related Quality of Life in Yogyakarta
}

Ninda Sari Wahyuningtyas ${ }^{1^{*}}$
Dyah Aryani Perwitasari ${ }^{2}$
Satibi 3
1Postgraduate Pharmacy Study
Program, Universitas Ahmad Dahlan,
Bantul, Special Region of Yogyakarta,
Indonesia
'Department of Pharmacy, Universitas
Ahmad Dahlan, Bantul, Special Region
of Yogyakarta, Indonesia
3Department of Pharmacy, Universitas
Gadjah Mada, Sleman, Special Region of
Yogyakarta, Indonesia
*email: nindasari23@gmail.com
Keywords:
FINDRISC
Type 2 Diabetes mellitus
Health-Related Quality of Life

\begin{abstract}
The number of people with type 2 diabetes mellitus (T2DM) in Indonesia increases every year. Control of the development of T2DM can be done by screening using Finnish Diabetic Risk Score (FINDRISC)-Indonesian. FINDRISC is a valid tool for estimating the risk of T2DM within the next 10 years. This condition can have a major impact on the estimated life span and quality of life in the future. The purpose of this research is to determine the relationship between FINDRISC-Indonesian and respondent characteristics with HRQoL from EuroQol-5 Dimension-5 Level (EQ-5D-5L) in Yogyakarta. The cross-sectional study was conducted on 125 respondents who met the inclusion criteria. The risk of developing T2DM was assessed using a validated and widely used FINDRISC (range 0-26 points), and quality of life was measured by the EQ-5D-5L instrument. Overall data were analyzed using the Pearson correlation test and Independent t-test. The results showed the domain of pain was the domain that reported most respondents' most problems $(28.8 \%)$. The respondent's utility value was $0.958 \pm 0.69$, and the VAS value was $79.4 \pm 0.7$. There was a significant difference in utility value based on age characteristics $(\mathrm{p}=$ $0.013)$. There is a relationship between age and utility value $(p=0.006)$ and FINDRISC score with utility value $(p=0.003)$. This study concludes that a high FINDRISC score affects the quality of life, and older age has a lower quality of life.
\end{abstract}

Received: August 7th, 2020

Accepted: December $25^{\text {th }}, 2020$

Published: February 28th, 2021

(C) 2021 Ninda Sari Wahyuningtyas, Dyah Aryani Perwitasari, Satibi. Published by Institute for Research and Community Services Universitas Muhammadiyah Palangkaraya. This is an Open Access article under the CC-BYSA License (http://creativecommons.org/licenses/by-sa/4.0/). DOI: https://doi.org/10.33084/bjop.v4i1.1579

\section{INTRODUCTION}

The rapid transition in economic development, industrialization, and globalization has led to lifestyle changes and increased life expectancy in most countries. This increase in lifestyle and cultural changes, including unhealthy dietary habits and a decrease in physical activity, has been accompanied by an increase in the prevalence of non-communicable (chronic) diseases, including diabetes mellitus (DM). In Indonesia, the number of type 2 diabetes mellitus (T2DM) patients has increased rapidly, not only in urban but also in rural areas $^{1}$, making Indonesia one of the countries with the most T2D cases in the world 2 .

In 2017, the International Diabetes Federation (IDF) ${ }^{2}$ reported that 10.3 million T2DM patients lived in Indonesia, which had increased to 10.7 million in 2019. Meanwhile, in the Special Region of Yogyakarta (Daerah Istimewa Yogyakarta, DIY), according to the Health Center Integrated Disease Survey report in 2016, DM, with 9,473 cases, was in the fourth position of the top 10 diseases in DIY. An examination of preventable lifestyle-related risk factors of T2DM identified overweight, abdominal obesity, sedentary lifestyle with high saturated fat, 
refined carbohydrate, total energy, and low dietary fiber intake ${ }^{3}$.

Unhealthy lifestyle habits, such as poor diet and lack of physical activity, are among the leading causes of mortality and disability in the western world. Among DM cases, more than $90 \%$ of patients have T2DM, and over $50 \%$ of cases are undetected 5 . Diabetes mellitus risk score is a straightforward, less time-consuming, noninvasive, and cost-effective approach to assess an individual's risk of undiagnosed T2DM and dysglycaemia ${ }^{6}$. Although the preference-based HealthRelated Quality of Life (HRQoL) effects of T2DM have been examined previously ${ }^{7}$, the association between estimated diabetes risk and $\mathrm{HRQ} \mathrm{L}$ is less understood. A few previous studies have reported an association between the estimated T2DM risk and HRQoL.

In this study, we have used Finnish Diabetic Risk Score (FINDRISC), one of the most frequently used instruments for assessing DM's risk ${ }^{8}$. Several noninvasive screening questionnaires for assessing the risk of T2DM have been developed in the past ten years, like FINDRISC and CANRISK (The Canadian Diabetes Risk Questionnaire). Compared to invasive tools, FINDRISC provides a feasible method to routinely screen the population to detect individuals with either undetected T2DM, abnormal glucose metabolism, or elevated risk to develop T2DM in the future. Although most T2DM risk questionnaires share similar characteristics and constructs, FINDRISC is currently one of the most widely validated and utilized T2DM risk scores ${ }^{9}$. FINDRISC assesses whether an individual has undiagnosed T2DM or dysglycaemia or the probability of developing T2DM during the following ten years ${ }^{10}$. The Indonesian version of the FINDRISC questionnaire has been validated, and the results are valid and reliable so that it can be used as a screening tool for T2DM in Indonesia ${ }^{11}$.
The previous study in Finland showed that low HRQoL was significantly and directly associated with the estimated risk of developing T2DM; the instruments used to measure the quality of life were 15D and SF-6D. Old age, lack of physical activity, obesity, and high blood glucose history were the FINDRISC factors most prominently associated with lower HRQoL ${ }^{12}$. FINDRISC was initially developed to assess future T2DM risk, subsequent studies have shown that it can also be used to detect prevalent abnormal glucose metabolism ${ }^{13}$ and predict other significant health outcomes, such as coronary heart disease, stroke, and overall mortality ${ }^{14}$.

Previously, no one had researched the relationship between the risk of T2DM and the quality of life in Yogyakarta, so this research was conducted in Yogyakarta, which has the second-highest number of DM cases in Indonesia. Since FINDRISC is a feasible tool for estimating a patient's T2DM risk in routine clinical practice, it could provide a simple way to evaluate a patient's HRQoL in clinical work and research. The use of additional separate HRQoL questionnaires would not be feasible ${ }^{12}$. This research has two objectives. First, to determine the relationship between respondent characteristics and utility. Second, to measure how HRQoL can be associated with T2DM risk estimates by examining the FINDRISC score and utility relationship.

\section{MATERIALS AND METHODS}

\section{Research design and participants}

This research was an observational study conducted prospectively with a cross-sectional study design conducted in April-November 2019. Observations were made on respondents who were not diagnosed with T2DM in Yogyakarta. The sampling targets include the academic community, cleaning service, and security guards at Universitas Ahmad Dahlan; the members of the Yogyakarta City Family Welfare Empowerment 
(Pemberdayaan Kesejahteraan Keluarga; PKK), the residents of the Cepoko Indah Bantul housing estate, and the employees of the Gunung Kidul Regional Development Planning Agency (Badan Perencanaan Pembangunan Daerah; Bappeda) office. The sampling technique in this research was consecutive sampling according to inclusion and exclusion criteria. The number of samples in this study was calculated based on the formula from Lemeshow et al..$^{15}$ with the population of Yogyakarta who was not diagnosed with T2DM as much as 3,558,865; the number of samples obtained 96 respondents. A larger number of samples will produce representative results, so this study took the number of samples as many as 125 respondents. Before conducting the study, respondents signed the informed consent form, then were interviewed to obtain demographic data, FINDRISC scores, and quality of life. This research has been approved by the Ethics Commission of the Faculty of Dentistry, Universitas Gadjah Mada, with No. 0095/KKEP/FKG-UGM/EC/2019.

\section{Research instruments}

The instruments used in this study were the Indonesian version of the FINDRISC, the EuroQoL-5 Dimension-5 Level (EQ-5D-5L), and the Indonesian version of the Visual Analog Scale (VAS). Risk score for T2DM: The instrument used to measure the risk score for T2DM was the Indonesian version of the FINDRISC, which was previously validated ${ }^{11}$. The questions in FINDRISC including age, body mass index (BMI), waist circumference, daily physical activity, consumption of vegetables/fruit, history of consumption of antihypertensives, history of high blood sugar levels, and family history of T2DM. Categorical response options were weighted (higher levels indicate significance larger) and summed to get a total risk score. Total scores ranged from 0 to 26, in which higher scores correspond to a greater risk of diabetes. The FINDRISC scores were categorized into less than 7 (low, estimated 1-100 developing disease), 7-11 (slightly elevated, estimated 1 in 25 develops disease), 12-14 (moderate, estimated 1 in 6 develops disease), 15-20 (high, estimated 1 in 3 develops the disease) and more than 20 (very high, estimated 1 in 2 develops the disease) $)^{12}$.

The questionnaire used to measure respondent's utility was the EQ-5D-5L and the VAS. The EQ-5D-5L questionnaire was a generic instrument with higher scores representing better health status consisting of five dimensions: mobility, self-care, daily activities, pain or discomfort, and anxiety or depression. Each dimension had five levels consist of level 1 (no problem), level 2 (slight or minor problematic), level 3 (moderate problematic), level 4 (severe problematic), and level 5 (unable or extreme problematic). General health status was measured by VAS with a value of 1-100, in which 0 was the worst health status, and 100 was the best health status. The EQ-5D-5L questionnaire used in this study was a validated standard Indonesian version 1.0 questionnaire with a population of Indonesians. This study's quality of life score was calculated using the Indonesian version of the EQ-5D-5L value set developed with the Indonesian population ${ }^{16}$.

\section{Data analysis}

Analyses were performed using Statistical Package for theSocial Science(SPSS) software version 23. Respondent characteristics data such as age, gender, occupation, income, BMI, waist circumference, physical activity, daily fruit/vegetable consumption, history of antihypertensive use, history of high blood sugar levels, and family history of diabetes were described descriptively in terms of means with Standard Deviation (SD). Analysis of the relationship between respondents' characteristics (gender, education, and occupation) with utility was examined using the Spearman correlation test. Meanwhile, to see the relationship between age and the 
FINDRISC score with utility was examined using the Pearson correlation test.

\section{RESULTS AND DISCUSSION}

\section{Demographic characteristic}

Characteristics of respondents in this study including age, gender, education, income, and occupation, while the characteristics of respondents based on FINDRISC consisted of age, BMI, waist circumference, daily physical activity, daily consumption of vegetables/fruit, history use of antihypertensives, history of high blood sugar levels and family history of diabetes. As presented in Table I, respondents aged $<45$ years (45.6\%), $45-54$ years were 34 (27.2\%), 55-64 years 28 (22.4\%) and 6 years older than 64 (4.8\%). Respondents in this study were more dominated by respondents aged $>45$ years. This was because the research targets were prioritized on respondents aged $>45$ years, where a person was more at risk of developing T2DM at $>45$ years of age, had a family history of having T2DM, and being overweight or obese. Previous research stated that individuals with obesity based on waist circumference and aged $\geq 50$ years could increase the risk of $\mathrm{T}_{2} \mathrm{DM}^{17}$. Asymptomatic children or adolescents who were obese and had two risk factors, for example, a first-generation family history of T2DM (mother/father/older sibling), should be screened. It further recommends that screening be started at the age of 10 (or the onset of puberty if puberty occurs at a younger age) and that screening was repeated every three years ${ }^{18}$.

The average BMI of respondents in this study was 25.35 $\pm 4.16 \mathrm{~kg} / \mathrm{m}^{2}$, so it could be seen that the average BMI of the respondents in this study was included in the overweight category. The BMI was divided into three categories consist of $<25 \mathrm{~kg} / \mathrm{m}^{2}$ (normal), $25-30 \mathrm{~kg} / \mathrm{m}^{2}$ (overweight), and $>30 \mathrm{~kg} / \mathrm{m}^{2}$ (obese). Respondents who had normal BMI were $48.8 \%$, overweight $28.8 \%$, and obese $12 \%$. Being overweight was an important predictor of T2DM, known as "diabetes"19.

Weight gain between the ages of 25-40 years results in the early onset of T2DM; the age difference at diagnosis of T2DM for individuals who had stable weight compared to severe weight gain was five years for men and three years for women ${ }^{20}$. The average waist circumference of the respondents was $93.41 \pm 11.43 \mathrm{~cm}$. In this study, the waist circumference for men and women was divided into three categories. Women's waist circumference consists of $<80 \mathrm{~cm}, 80-88 \mathrm{~cm}$, and $>88 \mathrm{~cm}$, while for men consists of $<94 \mathrm{~cm}, 94-102 \mathrm{~cm}$, and $>102 \mathrm{~cm}$.

Determining BMI and waist circumference were important to estimate the risk of T2DM, especially for those who had low or normal body weight because these two parameters affect T2DM. Using BMI or waist circumference alone will lead to an inadequate assessment of the risk of T2DM. The BMI and waist circumference serve as parameters for estimating general or abdomen fat mass. It was assumed that abdominal fat mass was crucial in the development of T2DM and other chronic diseases such as cardiovascular disease and cancer $^{21}$.

Maintenance of physical activity is an important focus for blood glucose management and health in individuals with diabetes and prediabetes. Exercise could improve blood glucose control in individuals with T2DM, reduce cardiovascular risk factors, contribute to weight loss and improve well-being 22 . Regular exercise could prevent or delay the development of T2DM 23 . As much as 59 (47.2\%) of the 125 respondents did not routinely perform physical activity $<30$ minutes per day. Structured lifestyle interventions that include physical activity performed for 150-175 minutes/week and dietary energy restriction targeting 5\% -7\% weight loss had shown a $40 \%-70 \%$ reduction in the risk of developing T2DM in individuals with intolerance disorders. 
Prehypertension and hypertension were independently and strongly associated with T2DM. The risk of diabetes incidence was significantly greater in individuals whose blood pressure was not well controlled than those who were well controlled ${ }^{24}$. Respondents who regularly consume antihypertensives such as ACE inhibitors were $15(12 \%)$. Although the clinical impact of blood pressure requires further analysis, active control of blood pressure in normal-prehypertensive individuals should be considered to prevent the development of T2DM. The pathophysiological mechanism that explains hypertension and T2DM was unclear, but several hypotheses had been proposed. High blood pressure had been shown to induce microvascular dysfunction, which may contribute to the pathophysiology of the development of T2DM closely related to hypertension, and biomarkers of endothelial dysfunction were predictors of T2DM independently ${ }^{25}$.

Before reaching T2DM status, a person with insulin resistance would reach the prediabetes stage, or we usually call Impaired Glucose Tolerance (IGT) and Impaired Fasting Glucose (IFG). Prediabetes was a serious health condition where blood sugar levels were higher than normal but not high enough to be diagnosed as diabetes. In this study, $10(8 \%)$ respondents had a history of high blood sugar levels. Prediabetes was associated with dysglycemia, central obesity, inflammation, and endothelial dysfunction. Oxidative stress contributes to the pathogenesis of cardiovascular disease $^{26}$.

Many antioxidant markers such as thiol/disulfide homeostasis, which had many cellular activities such as protection against antioxidants, detoxification, cell growth, and apoptosis, could be associated with triglyceride levels in early preclinical atherosclerosis, especially when plasma blood sugar levels were elevated $^{27}$. If a person had been declared to had prediabetes, precautions must be taken immediately to prevent the development of prediabetes into DM. Lifestyle intervention programs modify modifiable risk factors for prediabetes and diabetes by targeting obesity with increased physical activity and dietary changes.

Family history with T2DM was associated with various metabolic disorders and a strong risk factor for the development of $\mathrm{T}^{2} \mathrm{DM}^{28}$. A total of 41 (32.8\%) respondents had a first-degree family history with diabetes, and $14(11.2 \%)$ respondents had a seconddegree family history with diabetes. As many as 92 (73.6\%) respondents in this study were full and part-time workers, consisting of lecturers, civil servants, government/private employees, security guards, as well as cleaning services. Respondents who retirees were 8 $(6.4 \%)$ and $25(20 \%)$ of respondents were not working. The respondents' education level varied, and 68 (54.4\%) respondents had an income of $>$ Rp. 2,000,000,-. The results of measuring diabetes risk scores using FINDRISC showed that 52 (41.6\%) respondents had a fairly low score (7-11). The study sample characteristic was described in relation to FINDRISC categories in Table II. The average (SD) and median (range) FINDRISC scores were $8.136(4.3)$ and 8 (1 to 17), respectively.

\section{Description of the quality of life}

The EQ-5D-5L questionnaire consisted of five domains; mobility, self-care, daily activities, pain/ discomfort, and anxiety/depression. These dimensions had five levels; no problem, slight/minor problems, moderate problems, severe problems, and unable/extreme problems. Table III provides an overview of the percentage distribution of respondents based on each EQ-5D domain level. Based on Table III, it could be seen that the mobility domain of $0.8 \%(n=1)$ of respondents had severe problems, $3.2 \%(n=4)$ had a minor problem, and $96 \%(n=120)$ had no problems. For the self-care domain, there were no 
respondents who complained about problems $(100 \%$, $\mathrm{n}=125)$. In the domain of daily activities that were usually carried out, there were $0.8 \%(n=1)$ of respondents who complained about slight problems, and as many as $99.2 \%(n=124)$ of respondents admitted that there were no problems in their daily activities. In the pain/discomfort domain, $4 \%(n=5)$ of respondents complained of moderate problems, $24.8 \%(n=31)$ had a slight problem, and $79.2 \%(n=99)$ of respondents had no problems.

Table I. Characteristics research respondents

\begin{tabular}{lcc}
\hline \multicolumn{1}{c}{ Respondents characteristic $(\mathbf{n = 1 2 5 )}$} & $\mathbf{n}$ & $\mathbf{\%}$ \\
\hline Aged (year) & & \\
\hline$<45$ years & 57 & 45.6 \\
45-54 years & 34 & 27.2 \\
55-64 years & 28 & 28 \\
Older than 64 years & 6 & 4.8 \\
\hline Gender & & \\
\hline$\quad$ Male & 63 & 50.4 \\
$\quad$ Female & 62 & 49.6
\end{tabular}

Body Mass Index

\begin{tabular}{ccc}
\hline $\bar{x} \pm \mathrm{SD}(25.35 \pm 4.16) \mathrm{kg} / \mathrm{m}^{2}$ & & \\
\hline$<25 \mathrm{~kg} / \mathrm{m}^{2}$ & 61 & 48.8 \\
$25-30 \mathrm{~kg} / \mathrm{m}^{2}$ & 49 & 39.2 \\
$>30 \mathrm{~kg} / \mathrm{m}^{2}$ & 15 & 12
\end{tabular}

Waist circumference

\begin{tabular}{lcc}
\hline $\bar{x} \pm \mathrm{SD}(93.41 \pm 11.43) \mathrm{cm}$ & & \\
\hline$<94 \mathrm{~cm}(\mathrm{men}) /<80 \mathrm{~cm}$ (women) & 38 & 30.4 \\
$94-102 \mathrm{~cm}(\mathrm{men}) / 80-88 \mathrm{~cm}$ (women) & 36 & 28.8 \\
$>102 \mathrm{~cm}($ men $) />88$ (women) & 51 & 40.8 \\
\hline Less than 30 minutes of daily physical activity & 59 & 47.2 \\
\hline More than 30 minutes of daily physical activity & 66 & 52.8 \\
\hline History of blood pressure medication & 15 & 12 \\
\hline No history of blood pressure medication & 110 & 88 \\
\hline History of high blood glucose & 10 & 8 \\
\hline No history of high blood glucose & 115 & 92 \\
\hline Family diabetes & & \\
\hline No history of family diabetes & 70 & 56 \\
$1^{\text {st }}$ degree relative & 41 & 32.8 \\
$2^{\text {nd degree relative }}$ & 14 & 11.2 \\
\hline Occupation & & \\
\hline Employed Full time/Part time & 92 & 73.6 \\
Retired & 8 & 6.4 \\
Unemployed or on disability pension & 25 & 20 \\
\hline Education & & \\
\hline Elementary/Junior High & 23 & 18.4 \\
Senior High & 37 & 29.6 \\
Diploma/Bachelor & 38 & 30.4 \\
Master & 27 & 21.6 \\
\hline Income (Rp) & & \\
\hline$\leq 2.000 .000$ & 37 & 29.6 \\
$>2.000,000$ & 68 & 54.4 \\
Unknown/Have no income & 20 & 16 \\
\hline & & \\
\hline & & \\
\hline
\end{tabular}

Table II. The characteristics of the respondents across the FINDRISC categories

\begin{tabular}{|c|c|c|c|c|c|}
\hline \multirow{3}{*}{ Variable } & \multicolumn{5}{|c|}{ Finnish Diabetes Risk Score } \\
\hline & $<7$ & $7-11$ & $12-14$ & $15-20$ & $>20$ \\
\hline & $(n=46)$ & $(n=52)$ & $(n=13)$ & $(=14)$ & $(n=0)$ \\
\hline \multicolumn{6}{|l|}{ Age } \\
\hline$<45$ years & $26(56.5)$ & $24(46.1)$ & $5(38.4)$ & $2(14.2)$ & $0(0.0)$ \\
\hline 45 to 54 years & $14(30.4)$ & $12(23)$ & $4(30.7)$ & $4(28.5)$ & $0(0.0)$ \\
\hline 55 to 64 years & $5(10.8)$ & $15(28.8)$ & $4(30.7)$ & $4(28.5)$ & $0(0.0)$ \\
\hline$>64$ years & $1(2.1)$ & $1(1.9)$ & $0(0.0)$ & $4(28.5)$ & $0(0.0)$ \\
\hline \multicolumn{6}{|l|}{ BMI } \\
\hline$<25 \mathrm{~kg} / \mathrm{m}^{2}$ & $32(69.5)$ & $21(40.3)$ & $4(30.7)$ & $3(21.4)$ & $0(0.0)$ \\
\hline $25-30 \mathrm{~kg} / \mathrm{m}^{2}$ & $14(30.4)$ & 27 (51.9) & $4(30.7)$ & $5(35.7)$ & $0(0.0)$ \\
\hline$>30 \mathrm{~kg} / \mathrm{m}^{2}$ & $0(0.0)$ & $24(46.1)$ & $5(38.4)$ & $6(42.8)$ & $0(0.0)$ \\
\hline \multicolumn{6}{|c|}{ Waist circumference } \\
\hline $\begin{array}{l}<94 \mathrm{~cm} \\
(\mathrm{men}) /<80 \mathrm{~cm} \\
\text { (women) }\end{array}$ & $27(58.6)$ & $11(21.1)$ & $0(0.0)$ & $0(0.0)$ & $0(0.0)$ \\
\hline $\begin{array}{l}94-102 \mathrm{~cm} \\
\text { (men)/80-88 } \\
\mathrm{cm} \text { (women) }\end{array}$ & $14(30.4)$ & $18(34.6)$ & $1(7.7)$ & $1(7.1)$ & $0(0.0)$ \\
\hline $\begin{array}{l}>102 \mathrm{~cm} \\
(\text { men }) />88 \mathrm{~cm} \\
\text { (women) }\end{array}$ & $5(10.8)$ & $23(44.2)$ & $12(92.3)$ & $13(92.8)$ & $0(0.0)$ \\
\hline $\begin{array}{l}\text { Less than } 30 \\
\text { minutes of } \\
\text { daily physical } \\
\text { activity }\end{array}$ & $8(17.3)$ & $24(46.1)$ & $13(100)$ & $14(100)$ & $0(0.0)$ \\
\hline $\begin{array}{l}\text { History of } \\
\text { blood pressure } \\
\text { medication }\end{array}$ & $2(4.3)$ & $5(9.6)$ & $2(15.3)$ & $6(42.8)$ & $0(0.0)$ \\
\hline $\begin{array}{l}\text { History of } \\
\text { high blood } \\
\text { glucose }\end{array}$ & $0(0.0)$ & $3(5.7)$ & $2(15.3)$ & $5(35.7)$ & $0(0.0)$ \\
\hline \multicolumn{6}{|l|}{ Family diabetes } \\
\hline $\begin{array}{l}\text { No history of } \\
\text { family diabetes }\end{array}$ & $41(89)$ & $25(48)$ & $1(7.7)$ & $2(14.2)$ & $0(0.0)$ \\
\hline $\begin{array}{l}2^{\text {nd }} \text { degree } \\
\text { relative }\end{array}$ & $3(6.5)$ & 9 (17.3) & $1(7.7)$ & $1(7.1)$ & $0(0.0)$ \\
\hline $\begin{array}{l}1^{\text {st }} \text { degree } \\
\text { relative }\end{array}$ & $2(4.3)$ & 18 (34.6) & $11(84.6)$ & $11(78.5)$ & $0(0.0)$ \\
\hline
\end{tabular}

Table III. Distribution of respondents based on quality of life in each domain and level

\begin{tabular}{|c|c|c|c|c|c|}
\hline \multirow[b]{2}{*}{ Domain } & \multicolumn{5}{|c|}{ Percentage of Respondents (\%) } \\
\hline & $\begin{array}{l}\tilde{a} \\
\frac{0}{0} \\
0 \\
0 \\
0 \\
0 \\
\dot{z}\end{array}$ & 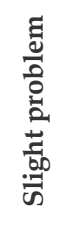 & 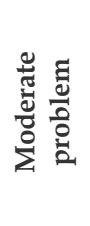 & 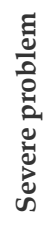 & 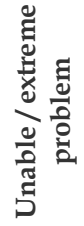 \\
\hline Mobility & 96 & 3.2 & 0 & 0.8 & 0 \\
\hline Selfcare & 100 & 0 & 0 & 0 & 0 \\
\hline Daily activities & 99.2 & 0.8 & 0 & 0 & 0 \\
\hline Pain/discomfort & 79.2 & 24.8 & 4 & 0 & 0 \\
\hline Anxiety/depression & 89.6 & 8.8 & 1.6 & 0 & 0 \\
\hline
\end{tabular}

For the anxiety/depression domain, there were $1.6 \%$ $(n=2)$ of respondents complained of moderate problems, $8.8 \%(n=11)$ of respondents complained about slight 
problems, and as many as $89.6 \%(\mathrm{n}=112)$ of respondents did not complain about a problem. It could be concluded that for level 2 (slight problems), the domain that most respondents complained about was the pain/discomfort domain, which was $24.8 \%(n=31)$, the anxiety/depression domain was $8.8 \%(n=11)$ respondents, the mobility domain was $3,2 \%(n=4)$ of respondents, and the last was the activity domain that was carried out by $0.8 \%(n=1)$. The average value of the respondent's utility and VAS in this study could be seen in Table IV. The utility value of the respondents was $0.958 \pm 0.69$, while the VAS value obtained was $79.04 \pm 0.71$. The average utility value in this study population of Indonesians was $0.91^{16}$. Compared with the utility value of T2DM patients, it was very different; the utility values of T2DM patients that had been studied previously were $0.75^{29}$ and 0.77 .

Table IV. The value of the respondent's utility

\begin{tabular}{lcc}
\hline & Dimention of EQ-5D & Value \\
\hline Utility & & $0.958 \pm 0.69$ \\
VAS & $79.04 \pm 0.71$ \\
\hline
\end{tabular}

The relationship between respondent characteristics and quality of life

The relationship between respondent characteristics and quality of life could be seen in Table $V$. The results of the analysis between respondents and utility characteristics found that age influenced the HRQoL of the respondents who participated in this study ( $\mathrm{p}$-value $=0.006,<0.05$ ). The correlation coefficient value indicating the level of correlation between age and utility was -0.246 . The correlation between age and utility was weak and negative; older respondents had a lower utility value. The ages of the respondents who participated in this study were very diverse, the lowest age was 18 years, and the highest age was 68 years. Complaints of illness or discomfort caused respondents' low utility value whose age was higher; most often, it was a pain in the joints. Other characteristics of respondents such as gender, education level, and occupation show a significance value $>0.05$, which indicates that in this study, gender, education level, and occupation had no relationship with HRQoL or not affects the HRQoL value of respondents.

\begin{tabular}{lccc}
\hline $\begin{array}{c}\text { Independent } \\
\text { variable }\end{array}$ & $\begin{array}{c}\text { Dependent } \\
\text { variable }\end{array}$ & $\begin{array}{c}\text { Correlation } \\
\text { coefficient }\end{array}$ & $\mathbf{p}$ \\
\hline Sex & & 0.79 & 0.382 \\
Age & Utility & -0.246 & $0.006^{*}$ \\
Education & & -0.046 & 0.61 \\
Job & -0.142 & 0.113 \\
${ }^{*}:<0.05$ & & &
\end{tabular}

\section{Relationship between FINDRISC and HRQoL}

The main objective of this study was to see the relationship between FINDRISC and HRQoL. Previous research had shown an association between low quality of life (QoL) and an increased risk of $\mathrm{T}^{2} \mathrm{DM}^{12}$. The following was the Pearson test table between the FINDRISC score and HRQoL. Table VI shows the Pearson correlation test results between the FINDRISC and the utility value, the results above indicate that the significance value obtained was 0.003 ( $p<0.05$ ). It could be concluded that the FINDRISC score with the HRQoL had a relationship in this study.

The correlation between the two variables could be seen from the Pearson correlation value, where the result was -0.265 . The correlation between the FINDRISC score and the utility value was weak and had a negative correlation. In this study, there was no relationship between the FINDRISC score and the VAS value where the p-value was $>0.05$. An oral glucose tolerance test (OGTT) was a valid tool for describing a patient's current glucose metabolism status. A self-reported history of high blood glucose may indicate ongoing glucose metabolism problems and reflect the individual's worry about their health and wellbeing.

Table VI. Relationship between FINDRISC and HRQoL score

\begin{tabular}{llcc}
\hline $\begin{array}{c}\text { Independent } \\
\text { variable }\end{array}$ & $\begin{array}{c}\text { Dependent } \\
\text { variable }\end{array}$ & $\begin{array}{c}\text { Correlation } \\
\text { coefficient }\end{array}$ & $\mathbf{p}$ \\
\hline FINDRISC & Utility & -0.265 & $0.03^{*}$ \\
FINDRISC & VAS & -0.166 & 0.65 \\
\hline${ }^{*}:<0.05$ & & &
\end{tabular}


The FINDRISC is a non-invasive comprehensive tool that can be used to estimate the risk of T2DM and other glucose metabolism disorders ${ }^{13}$ and morbidity and total mortality ${ }^{30}$. Previous research has shown that lifestyle interventions could effectively prevent the onset of $\mathrm{T}_{2} \mathrm{DM}^{31}$ in respondents with glucose intolerance disorders, especially in respondents with high FINDRISC scores $^{32}$.

The present study had strengths and potential weaknesses. First, the application of a widely used and validated instrument for diabetes risk and HRQoL. Second, consideration of the potential HRQoL effects of socioeconomic factors. A shortcoming to this study was the cross-sectional setting that did not allow examining changes in HRQoL over time in people with varying FINDRISC scores. This study was attended by respondents of various ages, ranging from young, middle-aged, and older individuals from Yogyakarta. Diabetes screening from a young age effectively prevents the development of T2DM, with healthier lifestyle changes.

\section{CONCLUSION}

This study found that age and FINDRISC score were negatively related to quality of life, where the higher the age and the FINDRISC score, the lower the respondent's quality of life.

\section{ACKNOWLEDGMENT}

The author would like to thank the academic community, cleaning service, and security guards at Universitas Ahmad Dahlan; the members of the Yogyakarta City Family Welfare Empowerment; the residents of the Cepoko Indah Bantul housing estate; and the employees of the Gunung Kidul Regional Development Planning Agency who have participated in this research and those who have participated in the data collection process.

\section{REFERENCES}

1. Ministry of Health of the Republic of Indonesia. InfoDatin Pusat Data dan Informasi Kementerian Kesehatan RI: Hari Diabetes Sedunia Tahun 2018. Jakarta, Indonesia: Ministry of Health of the Republic of Indonesia; 2018.

2. International Diabetes Federation. International Diabetes Federation Diabetes Atlas. 9th edition. Brusesels, Belgium: International Diabetes Federation; 2019.

3. Al-Moosa S, Allin S, Jemiai N, Al-Lawati J, Mossialos E. Diabetes and urbanization in the Omani population: an analysis of national survey data. Popul Health Metr. 2006;4:5. doi:10.1186/1478-7954-4-5

4. Booth FW, Roberts CK, Laye MJ. Lack of exercise is a major cause of chronic diseases. Compr Physiol. 2012;2(2):1143-211. doi:10.1002/cphy.c110025

5. Guariguata L, Whiting DR, Hambleton I, Beagley J, Linnenkamp U, Shaw JE. Global estimates of diabetes prevalence for 2013 and projections for 2035. Diabetes Res Clin Pract. 2014;103(2):137-49. doi:10.1016/j.diabres.2013.11.002

6. Lee WJ, Song KH, Noh JH, Choi YJ, Jo MW. Healthrelated quality of life using the EuroQol 5D questionnaire in Korean patients with type 2 diabetes. J Korean Med Sci. 2012;27(3):255-60. doi:10.3346/jkms.2012.27.3.255

7. Arifin B, Idrus LR, van Asselt ADI, Purba FD, Perwitasari DA, At Thobari J, et al. Health-related quality of life in Indonesian type 2 diabetes mellitus outpatients measured with the Bahasa version of EQ5D. Qual Life Res. 2019;28(5):1179-90. doi:10.1007/s11136-019-02105-z

8. Lindström J, Tuomilehto J. The diabetes risk score: a practical tool to predict type 2 diabetes risk. Diabetes Care. 2003;26(3):725-31. doi:10.2337/diacare.26.3.725

9. Featherstone T, Eurich DT, Simpson SH. Limited Effectiveness of Diabetes Risk Assessment Tools in Seniors' Facility Residents. Value Health. 2017;20(3):329-35. doi:10.1016/j.jval.2016.09.2403

10. Saleem SM, Khan SMS, Jan SS. Finnish Diabetic Risk Score: A Tool for Predicting Risk of Undiagnosed 
Type 2 Diabetes Mellitus. Ann Med Health Sci Res. 2017;7:295-8.

11. Pertiwi P. Validasi Finnish Diabetic Risk Score Versi Indonesia di Yogyakarta [master's thesis]. Yogyakarta, Indonesia: Universitas Ahmad Dahlan; 2020.

12. Väätäinen S, Cederberg $H$, Roine $R$, KeinänenKiukaanniemi S, Saramies J, Uusitalo H, et al. Does Future Diabetes Risk Impair Current Quality of Life? A Cross-Sectional Study of Health-Related Quality of Life in Relation to the Finnish Diabetes Risk Score (FINDRISC). PLoS One. 2016;11(2):e0147898. doi:10.1371/journal.pone.0147898

13. Zhang L, Zhang Z, Zhang Y, Hu G, Chen L. Evaluation of Finnish Diabetes Risk Score in screening undiagnosed diabetes and prediabetes among U.S. adults by gender and race: NHANES 1999-2010. PLoS One. 2014;9(5):e97865. doi:10.1371/journal.pone.0097865

14. Heidemann C, Boeing H, Pischon T, Nöthlings $U$, Joost HG, Schulze MB. Association of a diabetes risk score with risk of myocardial infarction, stroke, specific types of cancer, and mortality: a prospective study in the European Prospective Investigation into Cancer and Nutrition (EPIC)-Potsdam cohort. Eur J Epidemiol. 2009;24(6):281-8. doi:10.1007/s10654-0099338-7

15. Lemeshow S, Hosmer DW, Klar J, Lwanga SK. Adequacy of Sample Size in Health Studies. New Jersey, US: John Wiley \& Sons, Inc; 1990.

16. Purba FD, Hunfeld JAM, Iskandarsyah A, Fitriana TS, Sadarjoen SS, Ramos-Goñi JM, et al. The Indonesian EQ-5D-5L Value Set. Pharmacoeconomics. 2017;35(11):1153-65. doi:10.1007/s40273-017-0538-9

17. Trisnawati SK, Setyorogo S. Faktor Risiko Kejadian Diabetes Melitus Tipe II Di Puskesmas Kecamatan Cengkareng Jakarta Barat Tahun 2012. Jurnal Ilmiah Kesehatan. 2013;5(1):6-11.

18. American Diabetes Association. Standards of Medical Care in Diabetes-2019 Abridged for Primary Care Providers. Clin Diabetes. 2019;37(1):1134. doi:10.2337/cd18-0105

19. Astrup A, Finer N. Redefining type 2 diabetes: 'diabesity' or 'obesity dependent diabetes mellitus'? Obes Rev. 2000;1(2):57-9. doi:10.1046/j.1467789x.2000.00013.x
20. Schienkiewitz A, Schulze MB, Hoffmann K, Kroke A, Boeing $\mathrm{H}$. Body mass index history and risk of type 2 diabetes: results from the European Prospective Investigation into Cancer and Nutrition (EPIC)Potsdam Study. Am J Clin Nutr. 2006;84(2):427-33. doi:10.1093/ajen/84.1.427

21. Feller S, Boeing H, Pischon T. Body-mass-Index, Taillenumfang und Risiko für Diabetes mellitus Typ 2. Dtsch Arztebl Int. 2010;107(26):470-6. doi:10.3238/arztebl.2010.0470

22. Lin X, Zhang X, Guo J, Roberts CK, McKenzie S, Wu $W C$, et al. Effects of Exercise Training on Cardiorespiratory Fitness and Biomarkers of Cardiometabolic Health: A Systematic Review and Meta-Analysis of Randomized Controlled Trials. J Am Heart Assoc. 2015;4(7):e002014. doi:10.1161/jaha.115.002014

23. Colberg SR, Sigal RJ, Yardley JE, Riddell MC, Dunstan DW, Dempsey PC, et al. Physical Activity/Exercise and Diabetes: A PositionStatement of the American Diabetes Association. Diabetes Care. 2016;39(11):2065-79. doi:10.2337/dc16-1728

24. Kim MJ, Lim NK, Choi SJ, Park HY. Hypertension is an independent risk factor for type 2 diabetes: the Korean genome and epidemiology study. Hypertens Res. 2015;38(11):783-9. doi:10.1038/hr.2015.72

25. Meigs JB, Hu FB, Rifai N, Manson JE. Biomarkers of endothelial dysfunction and risk of type 2 diabetes mellitus. JAMA. 2004;291(16):1978-86. doi:10.1001/jama.291.16.1978

26. Hamilton SJ, Watts GF. Endothelial Dysfunction in Diabetes: Pathogenesis, Significance, and Treatment. Rev Diabet Stud. 2013;10(2-3):133-56. doi:10.1900/RDS.2013.10.133

27. Agarwal A, Hegde A, Yadav C, Ahmad A, Manjrekar PA, Srikantiah RM. Assessment of oxidative stress and inflammation in prediabetes-A hospital based cross-sectional study. Diabetes Metab Synd. 2016;10(2 Suppl 1):S123-6. doi:10.1016/j.dsx.2016.03.009

28. InterAct Consortium; Scott RA, Langenberg C, Sharp SJ, Franks PW, Rolandsson O, et al. The link between family history and risk of type 2 diabetes is not explained by anthropometric, lifestyle or genetic risk factors: the EPIC-InterAct study. Diabetologia. 2013;56(1):60-9. doi:10.1007/s00125-012-2715-x 
29. Perwitasari DA, UrbayatunS, Faridah IN, Masyithah $\mathrm{N}$. Relationship of therapeutic outcome with quality of life on type 2 diabetes mellitus patients in Abdul Azis Singkawang hospital. IOP Conf Ser Mater Sci Eng. 2017;259:012023. doi:10.1088/1757899X/259/1/012023

30. Silventoinen $K$, Pankow J, Lindström J, Jousilahti $P$, Hu G, Tuomilehto J. The validity of the Finnish Diabetes Risk Score for the prediction of the incidence of coronary heart disease and stroke, and total mortality. Eur J Cardiovasc Prev Rehabil. 2005;12(5):451-8.

doi:10.1097/01.hjr.0000174793.31812.21

31. Lindström J, Peltonen M, Eriksson JG, Ilanne-Parikka $\mathrm{P}$, Aunola $\mathrm{S}$, Keinänen-Kiukaanniemi $\mathrm{S}$, et al. Improved lifestyle and decreased diabetes risk over 13 years: long-term follow-up of the randomised Finnish Diabetes Prevention Study (DPS). Diabetologia. 2013;56(2):284-93. doi:10.1007/s00125012-2752-5

32. Lindström J, Peltonen M, Eriksson JG, Aunola S, Hämäläinen $\mathrm{H}$, llanne-Parikka $\mathrm{P}$, et al. Determinants for the effectiveness of lifestyle intervention in the Finnish Diabetes Prevention Study. Diabetes Care. 2008;31(5):857-62. doi:10.2337/dc07-2162 